\title{
Phototransformation of three herbicides: chlorbufam, isoproturon, and chlorotoluron. Influence of irradiation on toxicity
}

\author{
C. Tixier, ${ }^{1}$ L. Meunier, ${ }^{3}$ F. Bonnemoy, ${ }^{2}$ and P. Boule ${ }^{3 \dagger}$ \\ ${ }^{1}$ Laboratoire de Synthèse et Etude de Systèmes à Intérêt Biologique (SESIB, UMR 6504) \\ ${ }^{2}$ Laboratoire de Biologie Comparée des Protistes (UPRES A 6023) \\ ${ }^{3}$ Laboratoire de Photochimie Moléculaire et Macromoléculaire (UMR 6505), Université Blaise Pascal \\ (Clermont-Ferrand), F-63177 Aubière, cedex France
}

ABSTRACT. The direct phototransformations in aqueous solution of chlorbufam (I), chlorotoluron (II), and isoproturon (III) are compared.<smiles>C#CC(C)OC(=O)Nc1cccc(Cl)c1</smiles>

I<smiles>Cc1ccc(NC(=O)N(C)C)cc1Cl</smiles>

II<smiles>CC(C)c1ccc(NC(=O)N(C)C)cc1</smiles>

III

With I and II photohydrolysis (substitution of chlorine atom with formation of the corresponding hydroxylated derivative) is initially almost quantitative. It does not depend on irradiation wavelength in the range $250-300 \mathrm{~nm}$. In contrast with III the main reaction is a free radical rearrangement, the reaction being more efficient at $254 \mathrm{~nm}$ than at wavelengths longer than $270 \mathrm{~nm}$.

Compounds II and III were also irradiated on sand in the absence of water. Several photoproducts were identified, they result from elimination or oxidation of methyl groups of urea moiety.

The toxicity of photoproducts was determined using the standard Microtox ${ }^{\circledR}$ test (toxicity on the bacterium Vibrio fischeri). Photohydrolysis of I and II does not change much the toxicity of solutions whereas the oxidation, or at a lower scale the elimination of methyl group on the urea moiety, dramatically increases the toxicity.

\section{INTRODUCTION}

Chlorbufam (I), chlorotoluron (II), and isoproturon (III) are three selective herbicides acting by inhibition of photosynthesis [1]. I is a chlorinated phenylcarbamate, II and III are two substituted phenylureas, chlorinated and unchlorinated respectively. These compounds are spread in the environment where they are submitted to bio- and photodegradation. Their solubilities in water reported in the Pesticide Manual are $540 \mathrm{mg} \cdot \mathrm{L}^{-1}$, $74 \mathrm{mg} \cdot \mathrm{L}^{-1}$, and $65 \mathrm{mg} \cdot \mathrm{L}^{-1}$ for I, II, and III respectively [1] (in the present work the solubility of chlorbufam was evaluated at about $150 \mathrm{mg} \cdot \mathrm{L}^{-1}$ ). They are sufficient to allow the draining of these herbicides from soil to surface waters [2] where the photodegradation is a possible pathway for their elimination. As photoproducts can also be involved in the environmental pollution it is important to identify them. Indeed these degradation products may be less or more toxic than the parent compound (see Scheme 1).

To our knowledge no photochemical study has been carried out on chlorbufam. However this herbicide is similar to chlorpropham [1-methylethyl-(3chlorophenyl) carbamate] and with the latter photohydrolysis of $\mathrm{C}-\mathrm{Cl}$ bond accounts for more than $70 \%$

†E-mail: Pierre.BOULE@univ-bpclermont.fr of the transformation [3].

Patria et al. and Millet et al. studied the phototransformation of chlorotoluron in aqueous solution. The former observed the formation of a main unidentified photoproduct [4]. Millet et al. identified this product as 3(3-hydroxy-4-methylphenyl)-1,1-dimethylurea in solutions irradiated in polychromatic light (xenon lamp). A low percentage of acetonitrile (0.5-2\%) has been added to increase the solubility. The half-life of chlorotoluron was evaluated at one month in summer and more than one year in winter conditions [5].

Several studies have dealt with the phototransformation of isoproturon. Dureja et al. identified 11 photoproducts in an aqueous solution irradiated between 254 and $360 \mathrm{~nm}$. Products were isolated by preparative layer chromatography plates and analysed by GC-MS. These products result from hydroxylation of the ring in ortho position, or from oxidation or elimination of methyl groups on the urea moiety. The formation of 4-isopropylaniline and azobenzene derivatives was also observed [6]. Some of these photoproducts were obtained by irradiation in alcoholic solution or on soil [7]. Results of Magnard-Billard de Saint-Laumer [8, 9] are in good agreement with previous ones. It was also reported that the photodegradation rate of isoproturon alone in methanol is higher than that of formulated 
<smiles>C#CC(C)OC(=O)Nc1cccc(Cl)c1</smiles><smiles>Cc1ccc(NC(=O)N(C)C)cc1Cl</smiles>

II Clorotoluron<smiles>CC(C)c1ccc(NC(=O)N(C)C)cc1</smiles>

III Isoproturon

Scheme 1 I: 1-methyl-2-propynyl-(3-chlorophenyl) carbamate, II: 3-(3-chloro-4-methylphenyl)-1,1-dimethylurea, III: 3-(4-isopropylphenyl)-1,1-dimethylurea.

one in water. Patria et al. reported that isoproturon is rapidly phototransformed at $253.7 \mathrm{~nm}$ but the three photoproducts detected were not identified [4]. The photochemical half-life was evaluated at more than one year even in summer conditions [5]. The photodegradation is then relatively difficult in environmental conditions.

The aim of the present work is to study the initial reaction involved in the phototransformation of chlorbufam, chlorotoluron, and isoproturon irradiated at various wavelengths in aqueous solution. The attention is focused on the analysis of the main photoproducts initially formed in order to improve the understanding of mechanisms involved and to study the influence of the photoproducts on the toxicity of solutions. With compounds II and III the photodegradation in the absence of water is compared with phototransformation in aqueous solution.

\section{MATERIALS AND METHODS}

2.1. Reactants. Chlorbufam $99 \%$ and chlorotoluron $98 \%$ were purchased from Chem Service and Ciba Geigy respectively. Isoproturon of high purity was provided by Rhône-Poulenc Agrochimie. No significant impurity was detected in it by HPLC.

Sand Fontainebleau from OSI used for dispersion of herbicides was washed with water and maintained several hours at temperature higher than $500{ }^{\circ} \mathrm{C}$ to eliminate all organic substances. Water was purified on Milli-Q (Millipore) device. Methanol and acetonitrile (HPLC grade) used for HPLC were from Carlo-Erba.

Several chemicals purchased from Aldrich were used for the synthesis of reference compounds: N-methylformamide, 3-hydroxy-4-methylaniline, 4- isopropylaniline, dimethyl-carbamyl chloride, dimethylamine, and thionyl chloride.

\subsection{Synthesis of photoproducts.}

$\mathrm{Ct}_{1}$ : 3-(3-hydroxy-4-methylphenyl)-1,1-dimethylurea.

This compound was synthesized according to a method adapted from the work of Crosby and Tang [10]. It consists in the reaction between 5-amino-ocresol and dimethylcarbamyl chloride (in excess) in anhydrous THF (Yield 70\%).

NMR ${ }^{1} \mathrm{H}\left(400.1 \mathrm{MHz}\right.$, acetone $\left.\mathrm{D}_{6}\right) \delta$ ppm: 2.10 (s, 3H); 2.97 (s, 6H); $6.72(\mathrm{dd}, 1 \mathrm{H}, J=2.1 \mathrm{~Hz}$ and $8.1 \mathrm{~Hz}) ; 6.88$ $(\mathrm{d}, 1 \mathrm{H}, J=8.1 \mathrm{~Hz}) ; 7.52$ (s, NH); 7.87 (d, $1 \mathrm{H}, J=2.1 \mathrm{~Hz}$; $8.15(\mathrm{~s}, \mathrm{OH})$.

NMR ${ }^{13} \mathrm{C} \quad\left(100.6 \mathrm{MHz}\right.$, acetone $\left.\mathrm{D}_{6}\right) \quad \delta \mathrm{ppm}: 35.7$ $\left(\left(\mathrm{N}\left(\mathrm{CH}_{3}\right)_{2}\right) ; 106.7\left(\mathrm{C}_{2}\right) ; 110.5\left(\mathrm{C}_{6}\right) ; 117.5\left(\mathrm{C}_{4}\right) ; 129.9\right.$ $\left(\mathrm{C}_{5}\right) ; 139.5\left(\mathrm{C}_{1}\right) ; 155.2\left(\mathrm{C}_{3}\right) ; 155.9(\mathrm{CO})$.

MS: $194 \quad\left(\mathrm{M}^{+\cdot}\right) ; 149 \quad\left(\mathrm{M}-\mathrm{NH}\left(\mathrm{CH}_{3}\right)_{2}\right) ; 122 \quad(\mathrm{M}-$ $\left.\mathrm{CON}\left(\mathrm{CH}_{3}\right)_{2}\right) ; 72\left(\mathrm{CON}\left(\mathrm{CH}_{3}\right)_{2}\right)$.

$\mathrm{I}_{1}$ : 2 amino-5-isopropyl- $\mathrm{N}, \mathrm{N}$-dimethylbenzamide.

The first step consists in synthesizing 2-amino-5isopropyl benzoic acid as described by Tilley et al. [11]. In a second step the acid chloride is prepared and let to react with dimethylamine. (Yield 15\%).

NMR ${ }^{1} \mathrm{H}\left(400.1 \mathrm{MHz}, \mathrm{CDCl}_{3}\right) \delta \mathrm{ppm}: 1.20(\mathrm{~d}, 6 \mathrm{H}, J=$ $\left.6.9 \mathrm{~Hz}, \mathrm{CH}\left(\underline{\mathrm{CH}}_{3}\right)_{2}\right) ; 2.80\left(\mathrm{~m}, \underline{\mathrm{CH}}\left(\mathrm{CH}_{3}\right)_{2}\right) ; 3.20(\mathrm{~s}, 6 \mathrm{H}$, $\left.\mathrm{N}\left(\mathrm{CH}_{3}\right)_{2}\right) ; 4.15$ (s, $\left.2 \mathrm{H}, \mathrm{NH}_{2}\right) ; 6.67(\mathrm{~d}, 1 \mathrm{H}, J=8.3 \mathrm{~Hz})$; $6.96(\mathrm{~d}, 1 \mathrm{H}, J=2.0 \mathrm{~Hz}) ; 7.03(\mathrm{dd}, 1 \mathrm{H}, J=2.0 \mathrm{~Hz}$ and $J=8.3 \mathrm{~Hz})$.

NMR ${ }^{13} \mathrm{C}\left(100.1 \mathrm{MHz}, \mathrm{CDCl}_{3}\right) \delta$ ppm: $24.3\left(\mathrm{CH}\left(\mathrm{CH}_{3}\right)_{2}\right)$; $33.1\left(\mathrm{CH}\left(\mathrm{CH}_{3}\right)_{2}\right) ; 35.2\left(\mathrm{~N}\left(\mathrm{CH}_{3}\right)_{2}\right) ; 39.3\left(\mathrm{NCH}_{3}\right) ; 116.8$ $\left(\mathrm{C}_{3}\right) ; 120.3\left(\mathrm{C}_{1}\right) ; 125.7\left(\mathrm{C}_{6}\right) ; 128.6\left(\mathrm{C}_{4}\right) ; 137.9\left(\mathrm{C}_{5}\right) ; 143.1$ $\left(\mathrm{C}_{2}\right) ; 171.4(\mathrm{CO})$.

MS: $206\left(\mathrm{M}^{+\cdot}\right) ; 191\left(\mathrm{M}^{-\mathrm{CH}_{3}}\right) ; 162\left(\mathrm{M}-\mathrm{N}\left(\mathrm{CH}_{3}\right)_{2}\right) ; 134(\mathrm{M}-$ $\left.\mathrm{CON}\left(\mathrm{CH}_{3}\right)_{2}\right) ; 118 ; 91$.

\section{The formylated compounds.}

$\mathrm{Ct}_{2}$ : 3-(3-chloro-4-methylphenyl)-1-formyl-1-methylurea

$\mathrm{I}_{2}$ : 3-(4-isopropylphenyl)-1-formyl-1-methylurea and the demethylated products

$\mathrm{Ct}_{3}$ : 3-(3-chloro-4-methylphenyl)-1-methylurea

$\mathrm{I}_{3}$ : 3-(4-isopropylphenyl)-1-methylurea

were obtained by reaction of the corresponding phenylisocyanates with N-methylformamide or methylamine respectively.

\section{Didemethylated photoproducts.}

$\mathrm{Ct}_{4}$ : 3-chloro-4-methylphenylurea and $\mathrm{I}_{4}$ : 4-isopropylphenylurea

were synthesized according to the method proposed by Kulshrestha and Mukerjee [7] by reaction of the corresponding aniline with potassium cyanate.

The structure of all synthesized compounds was controlled by ${ }^{1} \mathrm{H}$ NMR and mass spectrometry (electron impact $70 \mathrm{eV}$ ).

The main photoproduct $\mathrm{Cb}$ formed by photohydrolysis of chlorbufam was identified by MS and ${ }^{1} \mathrm{H}$ NMR after isolation:

NMR ${ }^{1} \mathrm{H}\left(400 \mathrm{MHz}\right.$, acetone $\left.\mathrm{D}_{6}\right) \delta \mathrm{ppm}: 1.50\left(\mathrm{~d}, \mathrm{CH}_{3}\right)$; 3.00 (s, C $\equiv \mathrm{H}$ ); 5.44 (qd, $J=6.7$ and $2.15 \mathrm{~Hz}, \mathrm{CH}$ ); 6.51 
(m, $\left.\mathrm{H}_{4}\right) ; 6.99\left(\mathrm{~d}, J=8.3 \mathrm{~Hz}, \mathrm{H}_{6}\right) ; 7.09\left(\mathrm{t}, J=8.3 \mathrm{~Hz}, \mathrm{H}_{5}\right)$; 7.20 (t, $\left.J=2.2 \mathrm{~Hz}, \mathrm{H}_{2}\right) ; 8.32(\mathrm{~s}, \mathrm{OH}) ; 8.67(\mathrm{~s}, \mathrm{NH})$

MS (electrospray): $m / z 206(M+1)$ and $228(M+23)$

2.3. Irradiations. For kinetic and analytical studies solutions were irradiated at $254 \mathrm{~nm}$ with a low pressure mercury lamp, commonly called germicidal lamp. The lamp and the reactor in quartz were placed along both focal axes of a cylindrical mirror with an elliptic base. The photon flow received by the solution was evaluated at $7.0 \times 10^{15}$ photons $\cdot \mathrm{s}^{-1} \cdot \mathrm{cm}^{-3}$, using potassium ferrioxalate as the chemical actinometer.

For the isolation of photoproducts a device with 6 lamps in a cylindrical mirror was used, the reactor being along the symetry axis.

To study the influence of the irradiation wavelength, solutions were irradiated with 6 fluorescent lamps Duke GL 20 emitting between 275 and $350 \mathrm{~nm}$ with a maximum at $310 \mathrm{~nm}$ and also on the mercury lines 365 , 405,436 , and 546. However only wavelengths shorter than ca. $310 \mathrm{~nm}$ are efficient for the photodegradation of pesticides. The reactor was in quartz to prevent from the cut off effect of "Pyrex." Lamps were surrounded by a cylindrical mirror as in previous device.

Quantum yields were measured in monochromatic light at $275 \mathrm{~nm}, 276 \mathrm{~nm}$, or $280 \mathrm{~nm}$ (band width about $10 \mathrm{~nm}$ at mid-hight) using a xenon lamp equipped with a monochromator Schoeffel. This device provides a parallel beam that makes possible the determination of absorbed photon flow using Beer-Lambert law.

The irradiation of chlorotoluron and isoproturon on sand was carried out with a device consisting of a round-bottom flask (3 litres) presenting internal spikes for mixing the support, and rotating around a horizontal axis. It was irradiated with 4 fluorescent lamps Duke GL20 emitting at wavelengths longer than $275 \mathrm{~nm}$ with a maximum near $310 \mathrm{~nm}$. Wavelengths shorter than $290 \mathrm{~nm}$ were cut off by the flask. The herbicides were dispersed on sand using diethyl ether, the solvent being eliminated first by evaporation and then by keeping under vacuum overnight.

2.4. Analytical methods. UV spectra of solutions were recorded on CARY 3 (Varian).

Irradiated solutions were analysed by HPLC on a column $\mathrm{C}_{18} 250 \times 4 \mathrm{~mm}$. A photodiode array detector Waters was used for chlorbufam and a classical UV detection for chlorotoluron and isoproturon. The eluent was methanol/water 65:35 (for chlorbufam) and a mixture acetonitrile/water $60: 40 \mathrm{v} / \mathrm{v}$ for the other herbicides.

Isolated photoproducts were identified by ${ }^{1} \mathrm{H}$ NMR on Bruker AC 400 (400 MHz), and by mass spectrometry on Hewlett-Packard 5989 B (electronic impact $70 \mathrm{eV}$ ).

2.5. Test of toxicity (Microtox ${ }^{\circledR}$ ). The toxicity of photoproducts or the influence of irradiation on the toxicity of solutions was determined with Microtox ${ }^{\circledR}$ test. This test consists in determining the concentration $\left(\mathrm{EC}_{50}\right)$ in toxic compound that inhibits $50 \%$ of the natural luminescence of a marine bacterium Vibrio fischeri. The emission is measured after various exposure times, usually 5,15 , or $30 \mathrm{~min}$. A decrease of $\mathrm{EC}_{50}$ corresponds to an increase of toxicity.

Assays were carried out with a Microbics M500 analyser. All materials for analyses (test reagent, diluent, osmotic adjusting solution, reconstitution solutions) were supplied by Azur Environmental (Carlsbad, CA, USA).

\section{RESULTS}

3.1. UV absorption. Chlorbufam, chlorotoluron, and isoproturon have similar UV spectra. The maximum of the main absorption band is located near $240 \mathrm{~nm}$ as it appears in Table 1. A band of lower intensity is located near $280 \mathrm{~nm}$. The absorption is very low at wavelengths longer than $300 \mathrm{~nm}$. The UV spectrum of chlorbufam is given in Figure 1 as an example. The spectra of chlorotoluron and isoproturon are not significantly different.

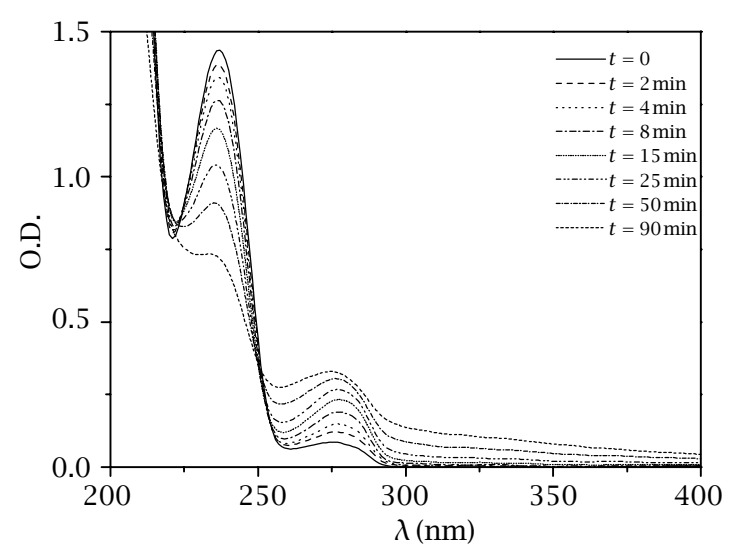

Figure 1. Evolution of the UV spectrum of an air-saturated solution of chlorbufam $1.02 \times 10^{-4}$ M irradiated at $254 \mathrm{~nm}$

The solubility of chlorbufam was determined by comparison of the UV absorption of a saturated solution with the UV absorption of a solution of known concentration containing a low percentage of methanol to increase the solubility. It was checked that the absorption was not modify by the percentage of methanol in the range $1-5 \%$.

3.2. Irradiation of chlorbufam. An air-saturated solution of chlorbufam $1.02 \times 10^{-4} \mathrm{M}$ was irradiated at $254 \mathrm{~nm}$. The evolution of the UV spectrum is given in Figure 1. The absorbance decreases between 224 and $250 \mathrm{~nm}$ and increases at longer wavelengths. The presence of two isosbestic points at 224 and $250 \mathrm{~nm}$ corresponds to a good accumulation of photoproducts. Several products can be detected on the HPLC chromatogram but only one $(\mathrm{Cb})$ accumulates as a primary photoproduct. The same reaction was observed in the absence of oxygen. The main photoproduct was isolated as indicated below for analysis.

A saturated solution $\left(6.7 \times 10^{-4} \mathrm{M}\right)$ was irradiated at $254 \mathrm{~nm}$ with the device with 6 lamps, till almost complete degradation of the reactant. Solution was extracted with ether. After evaporation and drying the main photoproduct was identified by MS and ${ }^{1} \mathrm{H}$ NMR 
Table 1. Main characteristics of the UV absorption spectra of the three herbicides.

\begin{tabular}{c|cc|cc}
\hline & $\lambda_{\max }(\mathrm{nm})$ & $\varepsilon\left(\mathrm{M}^{-1} \cdot \mathrm{cm}^{-1}\right)$ & $\lambda_{\max }(\mathrm{nm})$ & $\varepsilon\left(\mathrm{M}^{-1} \cdot \mathrm{cm}^{-1}\right)$ \\
\hline \multirow{2}{*}{ Chlorbufam } & 238 & 15200 & 276 & 910 \\
& & \pm 200 & & \pm 20 \\
\hline \multirow{2}{*}{ Chlorotoluron } & 241 & 16540 & 280 & 1370 \\
& & \pm 200 & & \pm 30 \\
\hline \multirow{2}{*}{ Isoproturon } & 240 & 16200 & 280 & 1180 \\
& & \pm 150 & (shoulder) & \pm 30 \\
\hline
\end{tabular}

(see Section 2.2). From NMR spectrum it was 95\% pure, the main impurity being chlorbufam for about $5 \%$ (see Scheme 2).<smiles>C#CC(C)OC(=O)Nc1cccc(O)c1</smiles>

Scheme 2

The isolated photoproduct $\mathrm{Cb}$ was used for the calibration of HPLC. The transformation is quantitative as far as $\mathbf{5 0 \%}$ transformed. It is also initially specific when solutions were irradiated in polychromatic light between 275 and $350 \mathrm{~nm}$. In this case, it was proved that the specificity of the reaction is not influenced by the concentration of chlorbufam nor by the presence of oxygen as far as $40 \%$ converted.

3.3. Irradiation of chlorotoluron. An air-saturated solution of chlorotoluron $1.6 \times 10^{-4} \mathrm{M}$ was irradiated at $254 \mathrm{~nm}$ in the device with one lamp described in Section 2.3. A decrease of the optical density was observed between 230 and $256 \mathrm{~nm}$ whereas an increase occured at longer wavelengths. The presence of two isosbestic points at $230 \mathrm{~nm}$ and $256 \mathrm{~nm}$ let assumed that the photoproduct(s) accumulate(s) in the solution.

Actually only one peak appears on the HPLC chromatogram. In order to isolate this photoproduct $\mathrm{Ct}_{1}$, one litre of a solution $3.3 \times 10^{-4} \mathrm{M}$ was irradiated up to $60 \%$ transformation with 6 low pressure mercury lamps. After concentration a mixture $\mathrm{Ct}_{1}+$ chlorotoluron was extracted from the irradiated solution with ethyl acetate. Then $\mathrm{Ct}_{1}$ was separated by column chromatography on silicagel. From ${ }^{1} \mathrm{H}$ NMR and mass spectrometry it was identified as 3-(3-hydroxy-4methylphenyl)-1,1-dimethylurea, see Scheme 3 (see Section 2.2).

To confirm this identification, this compound was synthesized as described in Section 2.2. HPLC retention time and spectral data (NMR, MS) were identical. The synthesis of $\mathrm{Ct}_{1}$ allowed the calibration of HPLC and the evaluation of the yield. It was deduced that the conversion is initially quantitative. When the transformation of chlorotoluron reaches $80 \%$ the formation of

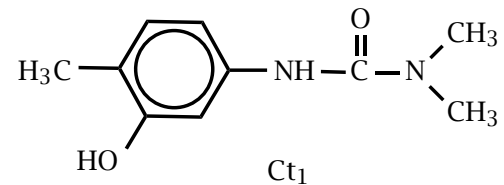

Scheme 3

$\mathrm{Ct}_{1}$ accounts for $70-80 \%$ of chlorotoluron converted as it appears in Figure 2.

The same photoproduct was obtained when a solution was irradiated at $280 \mathrm{~nm}$ i.e., in the other absorption band, and the quantum yield was the same taking into account the accuracy of the measurement as it is reported in Table 2 .

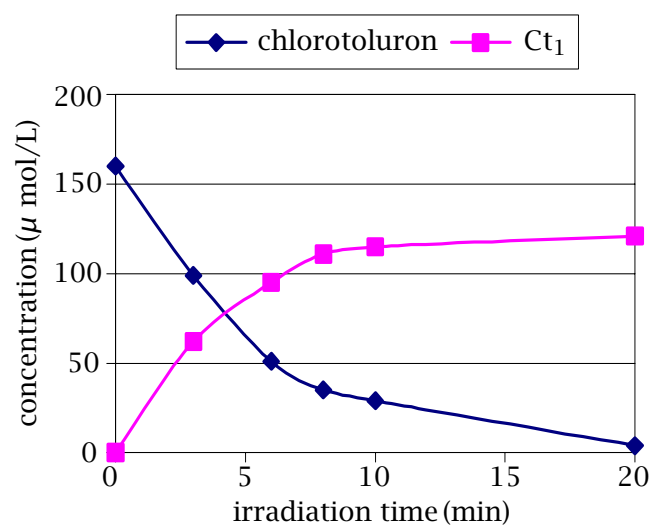

Figure 2. Disappearance of chlorotoluron and formation of product $\mathrm{Ct}_{1}$ in an air-saturated solution $1.6 \times 10^{-4} \mathrm{M}$ irradiated at $254 \mathrm{~nm}$.

3.4. Irradiation of isoproturon. An air-saturated solution of isoproturon $0.97 \times 10^{-4} \mathrm{M}$ was irradiated at $254 \mathrm{~nm}$. The absorption decreases between 236 and $256 \mathrm{~nm}$ and increases at longer wavelengths. Two isosbestic points are localized at 236 and $256 \mathrm{~nm}$ on the UV spectra of irradiated solutions (Figure 3).

Only one photoproduct $\mathrm{I}_{1}$ appears on the HPLC chromatogram of an irradiated solution. Its retention time is lower than the retention time of isoproturon. In order to isolate and identify this product a more concentrated solution $\left(3.4 \times 10^{-4} \mathrm{M}\right)$ was irradiated in the device with 6 lamps up to $60 \%$ transformation. After concentration 
Table 2. Quantum yield of phototransformation of the three herbicides in air saturated solution.

\begin{tabular}{c|c|c|c}
\hline & $\mathrm{C}\left(10^{-4} \mathrm{~mol} \cdot \mathrm{L}^{-1}\right)$ & $\lambda(\mathrm{nm})$ & $\phi$ \\
\hline \multirow{2}{*}{ Chlorbufam } & 6.56 & 254 & $0.047 \pm 0.005$ \\
& 6.84 & 276 & $0.058 \pm 0.005$ \\
\hline \multirow{3}{*}{ Chlorotoluron } & 1.60 & 254 & $0.031 \pm 0.003$ \\
& 1.79 & 280 & $0.037 \pm 0.003$ \\
& 0.24 & xenon lamp [5] & $0.055-0.095^{* \#}$ \\
\hline \multirow{3}{*}{ Isoproturon } & 1.06 & 254 & $0.0020 \pm 0.0005$ \\
& & 275 & $4.5 \times 10^{-4} \pm 5 \times 10^{-5}$ \\
& 0.24 & xenon lamp [5] & $4 \times 10^{-3 *}$ \\
\hline
\end{tabular}

\# according to $\mathrm{pH},{ }^{*}$ in the presence of $\mathrm{CH}_{3} \mathrm{CN} 0.5 \%$.

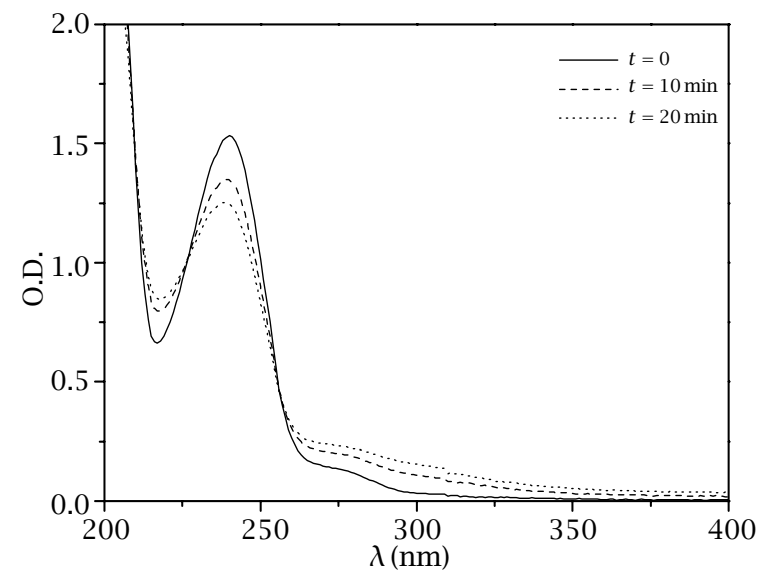

Figure 3. Evolution of the UV spectrum of an air-saturated solution of isoproturon $0.97 \times 10^{-4}$ M irradiated at $254 \mathrm{~nm}$.

the solution was extracted with ether and product $\mathrm{I}_{1}$ was isolated and purified by chromatography on silicagel. Product $\mathrm{I}_{1}$ was identified as 2-amino-5-isopropyl$\mathrm{N}$-N-dimethylbenzamide from ${ }^{1} \mathrm{H}$ NMR and mass spectrometry, see Scheme 4 (see Section 2.2).

To confirm this identification $\mathrm{I}_{1}$ was synthesized as indicated in Section 2.2. Photoproduct and synthesized compound had the same HPLC retention time and spectral data (NMR, MS). The synthesized compound was used to calibrate the HPLC. It was deduced that $\mathrm{I}_{1}$ accounts for about $66 \%$ of isoproturon converted in airsaturated solution. The same photoproduct was obtained in deoxygenated solution but the formation rate was about $20 \%$ higher. The chemical yield was evaluated at $71 \%$. In contrast product $I_{1}$ is not observed when solutions are irradiated at wavelengths longer than $275 \mathrm{~nm}$ using lamps GL20. In these conditions no photoproduct was identified. It was previously reported by Kotzias and Korte that this rearrangement (in the case of monuron) is more efficient at short wavelengths [12].

3.5. Kinetic study. The disappearance quantum yields of the three herbicides were measured at 275,276 , or<smiles>CC(C)c1ccc(N)c(Cl)c1</smiles>

$\mathrm{I}_{1}$

Scheme 4

$280 \mathrm{~nm}$ using the parallel beam obtained with a xenon lamp equipped with a monochromator. Values are gathered in Table 2. However some measurements were carried out at $254 \mathrm{~nm}$ in conditions of almost total absorption of light in order to observe a possible wavelength effect. With chlorbufam and chlorotoluron quantum yield has the same value in both absorption bands, whereas with isoproturon it is significantly lower at $275 \mathrm{~nm}$ than at $254 \mathrm{~nm}$.

3.6. Irradiation on sand. In order to study the influence of water on the photochemical behaviour, chlorotoluron and isoproturon were irradiated in dispersed state on sand in the absence of water. This technique was successfully used for diuron [13]. With this compound elimination or oxidation of methyl groups on the urea moiety (formation of formylated derivative) was observed. With chlorotoluron and isoproturon $5 \mathrm{mg}$ were dispersed on $100 \mathrm{~g}$ of sand using diethylether. After elimination of ether, dispersed herbicides were irradiated at $\lambda>290 \mathrm{~nm}$ with the device shortly described in Section 2.3. Then unreacted compound and photoproducts were extracted with methanol and analysed by HPLC.

The transformation rate was much lower than in aqueous solution and it decreased with irradiation time. This phenomenon may be attributed to an adsorption of sand on the flask (diffusion of light) or to a nonuniform dispersion of substrate on the sand. (The formation of microcrystals of substrate should make difficult the complete photodegradation because of the screen effect of products formed at the surface of microcrystals). 
<smiles>Cc1ccc(NC(=O)N(C)C=O)cc1Cl</smiles><smiles>CNC(=O)Nc1ccc(C)c(Cl)c1</smiles><smiles>CC(C)c1ccc(NC(=O)N(C)C=O)cc1</smiles><smiles>CNC(=O)Nc1ccc(C(C)C)cc1</smiles>

Scheme 5

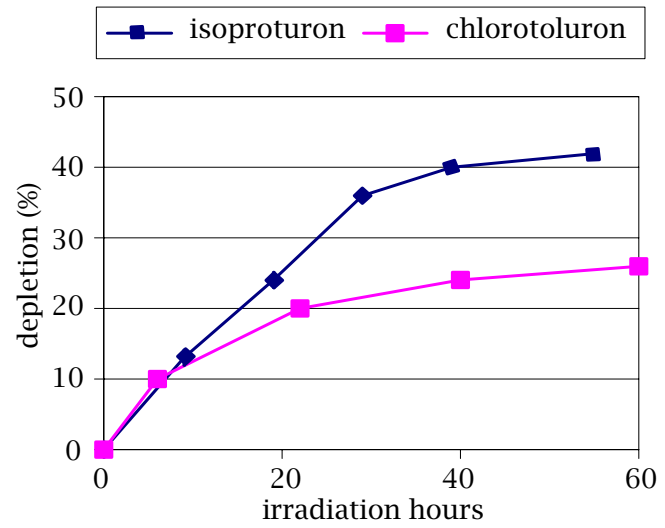

Figure 4. Phototransformation of chlorotoluron and isoproturon dispersed on sand $(5 \mathrm{mg} / 100 \mathrm{~g})$.

Several photoproducts were detected on HPLC chromatogram, but the amounts were too low for isolation.

For identification, compounds resulting from oxidation (formylated derivatives $\mathrm{Ct}_{2}$ and $\mathrm{I}_{2}$ ) or elimination of one methyl group $\left(\mathrm{Ct}_{3}\right.$ and $\left.\mathrm{I}_{3}\right)$, and products resulting from the elimination of both methyl groups of urea moiety $\left(\mathrm{Ct}_{4}\right.$ and $\left.\mathrm{I}_{4}\right)$ were synthesized. By comparison of their HPLC retention times, the products formed after irradiation of chlorotoluron in the absence of water correspond to compounds $\mathrm{Ct}_{2}$ and $\mathrm{Ct}_{3}$. Similarly, $\mathrm{I}_{2}$ and $\mathrm{I}_{3}$ were detected during the phototransformation of isoproturon on sand. But in both cases, no quantitative evaluation was possible.(see Scheme 5)

3.7. Microtox ${ }^{\circledR}$ text. The toxicity of herbicides and photoproducts was tested on Vibrio fischeri with Microtox ${ }^{\circledR}$ technique as indicated in Section 2.5. Results are gathered in Table 3.

With chlorbufam the toxicity of unirradiated solution $5 \times 10^{-4} \mathrm{M}$ was compared with toxicity of solutions irradiated up to 15,33 , and $56 \%$ of transformation. No significant change was observed. It can be assumed that the total number of molecules stay unchanged. It can be deduced that the product of photohydrolysis and parent product have similar toxicities. With the two other herbicides the toxicity of each photoproduct identified and synthesized was compared with the toxicity of parent compound. It clearly appears that, except for the product of photohydrolysis of chlorotoluron, photoproducts are much more toxic for Vibrio fischeri than the parent herbicide. Among all the compounds tested, the products of N-didemethylation and the formylated derivatives lead to the more important biological effects observed on the bacterium.

\section{MECHANISM}

The formation of hydroxylated derivatives initially quantitative with chlorbufam and chlorotoluron is at tributed to a photohydrolysis i.e., a heterolytic substitution of chlorine involving a molecule of water. It is not influenced by the presence of oxygen. Such a reaction was previously reported for 3-chloroaniline, chlorpropham [3], dichloroanilines [14], diuron [13], etc. (see Scheme 6)

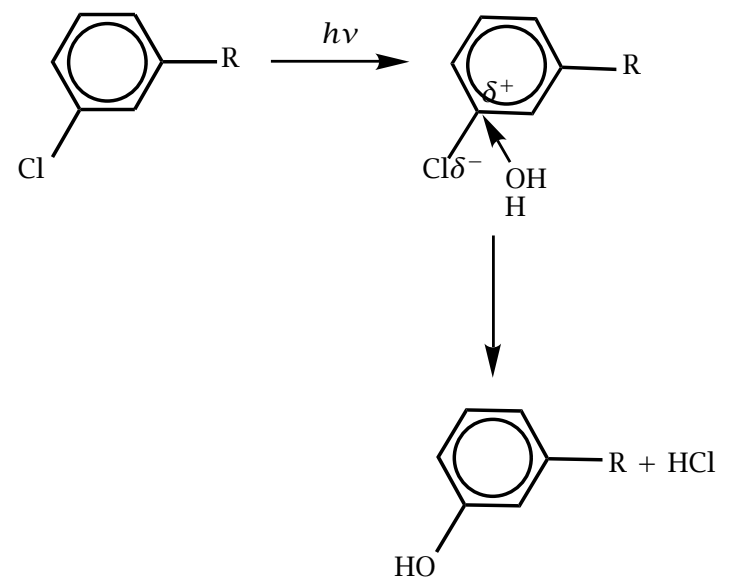

Scheme 6

The formation of product $\mathrm{I}_{1}$ from isoproturon results from a radical scission and rearrangement. Such a reaction was previously reported in the case of naphthoxyacetic acid [15], fenuron [16], and monuron [12]. With the latter it was reported to be more efficient at short wavelengths (see Scheme 7).

In the absence of water the two main photoproducts initially formed with chlorotoluron and isoproturon result from the elimination or oxidation of a methyl group 
Table 3. Evaluation of the toxicity of photoproducts with Microtox ${ }^{\circledR}$ test (exposure time: 5 min).

\begin{tabular}{|c|c|c|}
\hline \multicolumn{3}{|l|}{ Chlorbufam (irradiated solutions) } \\
\hline irradiation time (min) & $\%$ transformation & $\mathrm{EC}_{50}\left(\mu \mathrm{mol} \cdot \mathrm{L}^{-1}\right)$ \\
\hline 0 & 0 & 1530 \\
\hline 15 & 15 & 1140 \\
\hline 40 & 33 & 1340 \\
\hline 70 & 56 & 2000 \\
\hline \multicolumn{3}{|l|}{ Chlorotoluron (toxicity of photoproducts) } \\
\hline neat chlorotoluron & & $981^{*}$ \\
\hline $\mathrm{Ct}_{1}$ (photohydrolysis on the ring) & & $2310^{*}$ \\
\hline $\mathrm{Ct}_{2} \mathrm{R}_{\mathrm{C}}-\mathrm{NCH}_{3} \mathrm{CHO}$ & & 19 \\
\hline $\mathrm{Ct}_{3} \mathrm{R}_{\mathrm{C}}-\mathrm{NHCH}_{3}$ & & 100 \\
\hline $\mathrm{Ct}_{4} \mathrm{R}_{\mathrm{C}}-\mathrm{NH}_{2}$ & & 88 \\
\hline \multicolumn{3}{|l|}{ Isoproturon (toxicity of photoproducts) } \\
\hline neat isoproturon & & 128 \\
\hline $\mathrm{I}_{1}$ (rearrangement) & & 63 \\
\hline $\mathrm{I}_{2} \mathrm{R}_{i}-\mathrm{NCH}_{3} \mathrm{CHO}$ & & 2.2 \\
\hline $\mathrm{I}_{3} \mathrm{R}_{i}-\mathrm{NHCH}_{3}$ & & 72 \\
\hline $\mathrm{I}_{4} \mathrm{R}_{i}-\mathrm{NH}_{2}$ & & 9.7 \\
\hline$-\mathrm{NH}-\mathrm{CO}-$ ) & & \\
\hline
\end{tabular}

* extrapolated values ( $E C_{50}>$ higher than solubility).

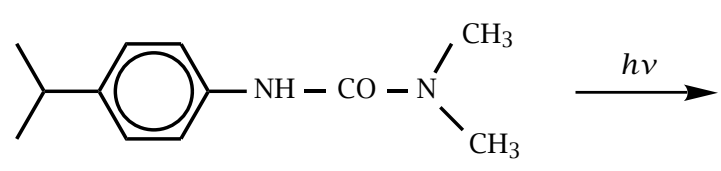<smiles>CC(C)c1ccc(N[14C](=[GeH2])N(C)C)cc1</smiles><smiles>CC(C)c1ccc(N)c(C(=O)N(C)C)c1</smiles> 
on the urea moiety. The same reactions were observed with diuron [13]. With the latter it was experimentally proved that demethylated product can be formed in the absence of oxygen.

A mechanism involving the intermediate formation of a methylenolate hydrolysed during HPLC analysis was tentatively proposed. Similar mechanism can be suggested for chlorotoluron and isoproturon but not experimentally proved.

The oxidation of methyl group is assumed to involve a hydrogen bond between methyl and carbonyl groups as it was proposed in the case of diuron [13] (see Scheme 8).<smiles>[3H]NC(=O)N1CC(=O)N1C</smiles><smiles>[3H]NC(=O)N(C)CO</smiles><smiles>CN(C=O)C(=O)N[AlH2]</smiles>

Scheme 8

\section{CONCLUSIONS}

The presence of a halogen atom on the ring has a significant influence on the photochemical behaviour of phenylurea herbicides in aqueous solution: chlorotoluron and isoproturon have completely different reactivities.

Photohydrolysis i.e., heterolytic substitution of a halogen atom by $\mathrm{OH}$ involving a molecule of water is the main reaction observed with meta-chlorinated aromatic herbicides chlorotoluron and chlorbufam.

A free radical rearrangement is the main reaction ob- served with isoproturon irradiated at $254 \mathrm{~nm}$ in aqueous solution, but this reaction is not observed when isoproturon is irradiated near $300 \mathrm{~nm}$.

In the absence of water the irradiation of chlorotoluron and isoproturon leads to the oxidation or the elimination of a methyl group of the urea moiety.

Photohydrolysis or photochemical rearrangement do not significantly change the toxicity of studied herbicides on Vibrio fischeri, whereas the elimination of a methyl group of the urea moiety and above all the formation of a formylated derivative dramatically increases the toxicity.

\section{ACKNOWLEDGEMENTS}

The authors are grateful to Rhône-Poulenc Agrochimie (France) for providing pure isoproturon used in this study and to D. Harakat for his efficient assistance in mass spectrometry.

\section{REFERENCES}

[1] C. Tomlim, The Pesticide Manual, 10 ed., The Bath Press, 1994, 170, 195, 611.

[2] M. Garmouna, M. J. Teil, M. Blanchard, and M. Chevreuil, Sci. Total Environ. 224 (1998), 93.

[3] B. David, M. Lhote, V. Faure, and P. Boule, Water Res. 32 (1998), 2451.

[4] L. Patria, M. Griseau, O. Le Brun, N. Merlet, and M. Doré, J. Europ. Hydrol. 26 (1995), 101.

[5] M. Millet, W. U. Palm, and C. Zetzsch, Environ. Toxicol. Chem. 17 (1998), 258.

[6] P. Dureja, S. Walia, and K. K. Sharma, Toxicol. Environ. Chem. 34 (1991), 65.

[7] G. Kulshrestha and K. Mukerjee, Pestic. Sci. 17 (1986), 489.

[8] C. Magnard-Billard de Saint-Laumer, Ph.D. thesis, Lyon, France, 1995.

[9] C. de Saint-Laumer, C. Emmelin, and P. Méallier, Fresenius Environ. Bull. 6 (1997), 529.

[10] D. G. Crosby and C. S. Tang, J. Agric. Food Chem. 17 (1969), 1041

[11] J. W. Tilley, R. A. Le Mahieu, M. Carson, and R. W. Kierstead, J. Med. Chem. 23 (1980), 92.

[12] D. Kotzias and F. Korte, Ecotox. Environ. Safety 5 (1981), 503.

[13] J. Jirkovský, V. Faure, and P. Boule, Pestic. Sci. 50 (1997), 42.

[14] K. Othmen and P. Boule, J. Photochem. Photobiol. A: Chem. 121 (1999), 161.

[15] M. J. Climent and M. A. Miranda, J. Agric. Food Chem. 45 (1997), 1916.

[16] J. P. Aguer and Richard C., Pestic. Sci. 46 (1996), 151. 


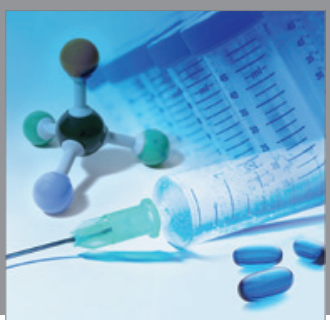

International Journal of

Medicinal Chemistry

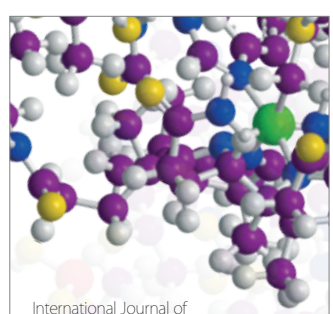

Carbohydrate Chemistry

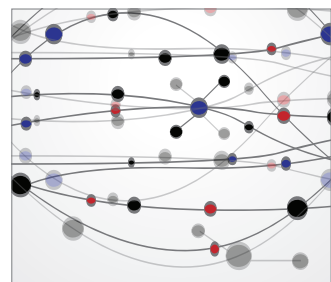

The Scientific World Journal
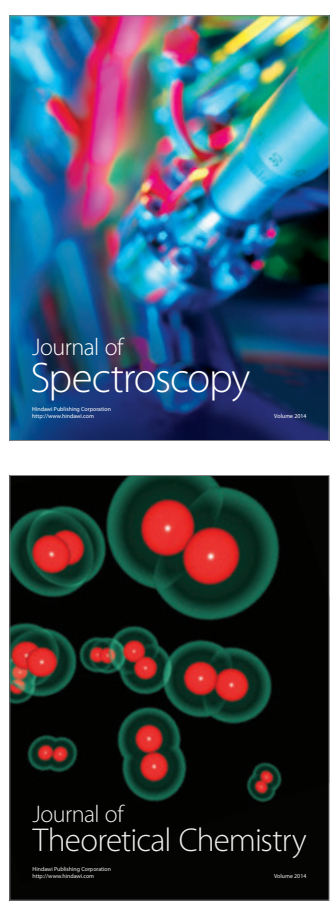
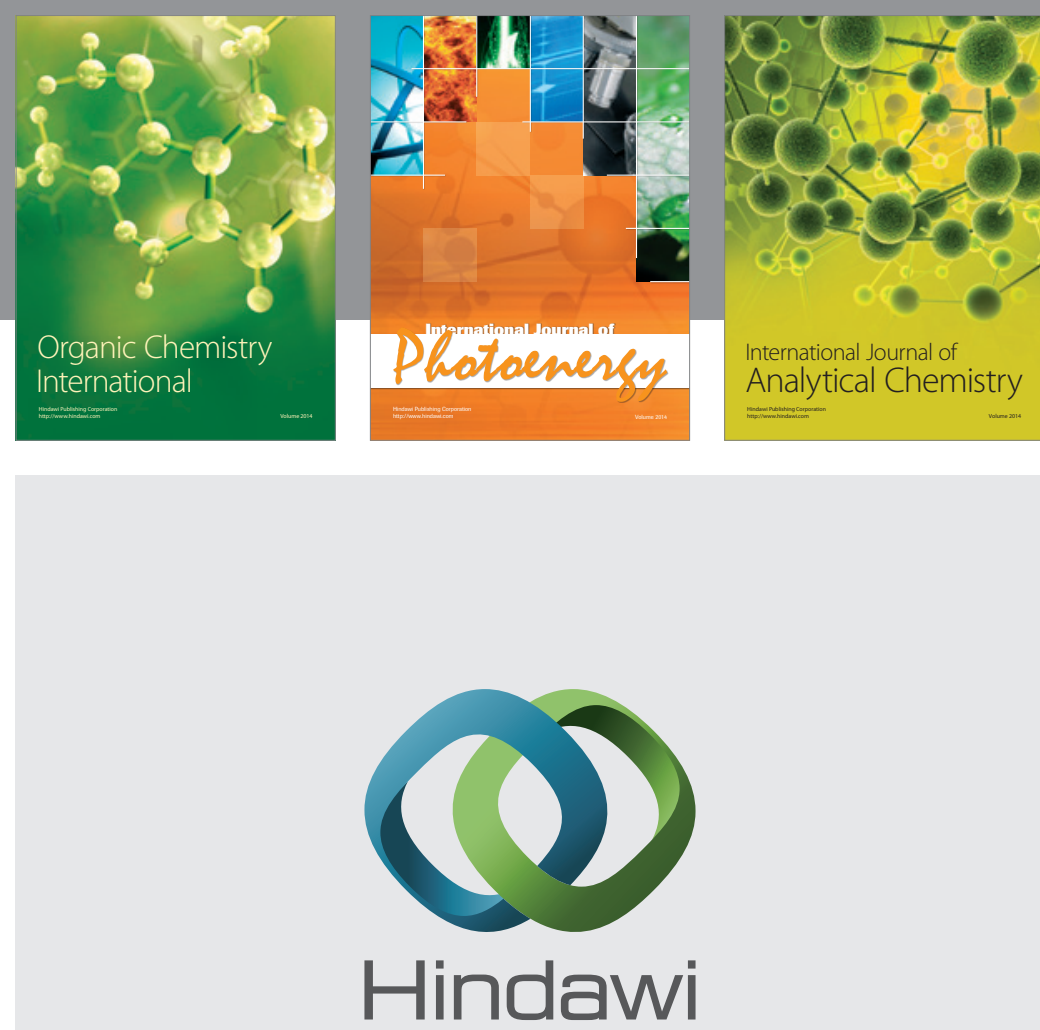

Submit your manuscripts at

http://www.hindawi.com
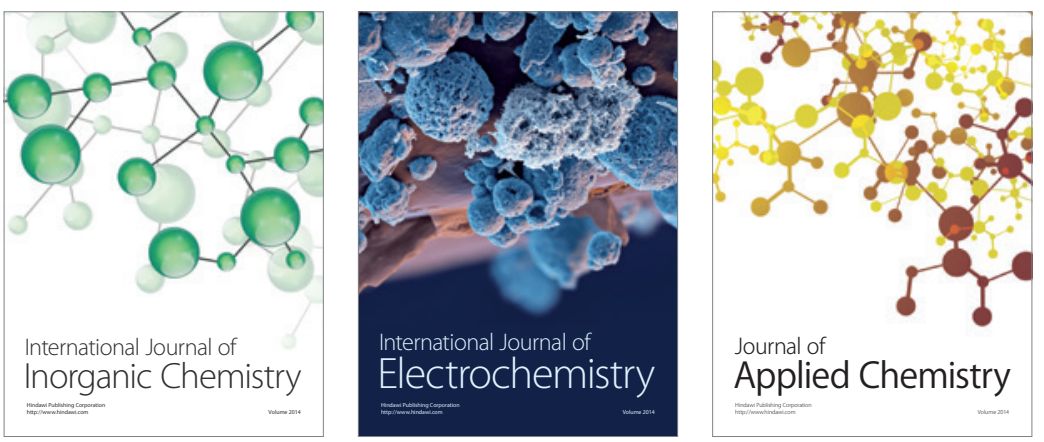

Journal of

Applied Chemistry
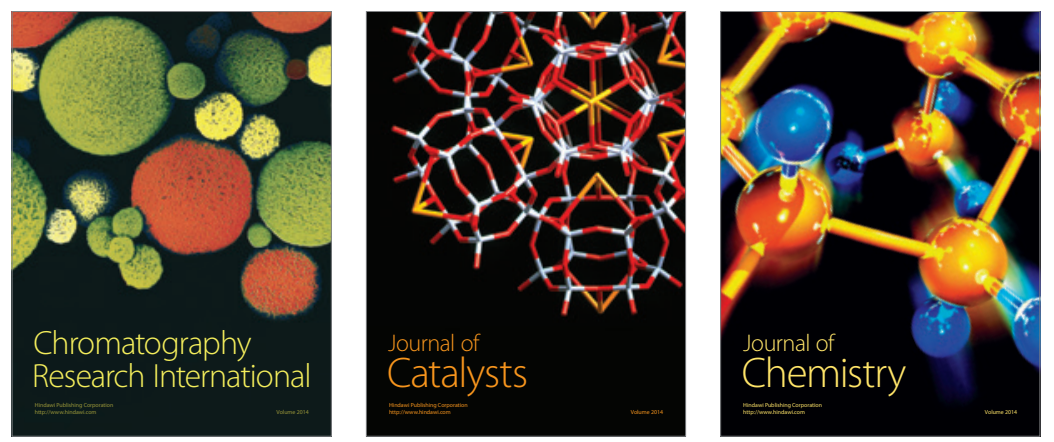
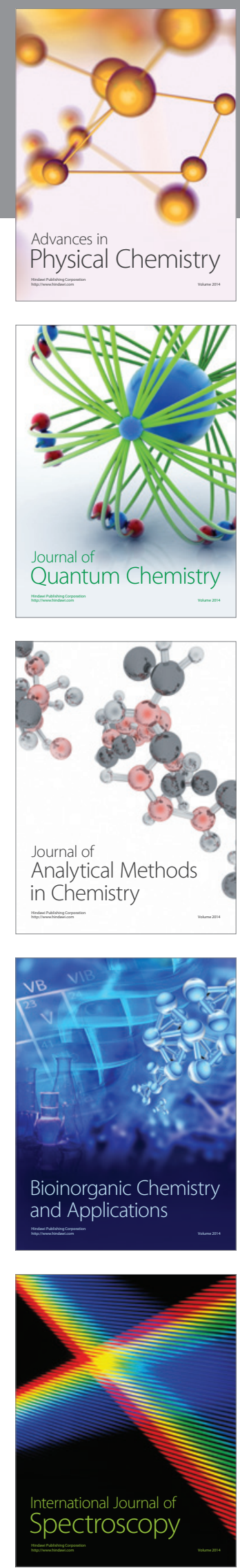